\title{
GUADALAJARA Y MADRID. POR UNA COMUNIDAD IBEROAMERICANA DE NACIONES
}

\section{Jesus Silva-Herzog $(*)$}

"En el mundo en que vivimos -configurado por los problemas a escala universal- no cabría la desunión de una comunidad como la nuestra. Debemos estar unidos para convertir en realidad nuestras posibilidades de conjunto, lo que será la mejor forma de mantener la individualidad nacional y su virtualidad esencial." (1)

Con estas palabras Juan Carlos I conmemoraba, hace casi 16 años, el 12 de octubre de 1976, en Cartagena de Indias, Colombia, el encuentro de dos mundos. Lo que entonces parecía un simple sueño comienza a hacerse realidad en la I Cumbre de Jefes de Estado y de Gobierno Iberoamericanos, que tuvo lugar en Julio del año pasado en Guadalajara, Mexico.

En este mundo de creciente regionalización y globalización, para mantener efectivamente la identidad y soberanía nacionales es necesario participar de manera activa en la toma de decisiones internacionales que a todos nos afectan. No podemos permanecer pasivos ante los cambios. Ya pasó a la historia la época en que la voz de una nación sola se hacía escuchar. Ahora hay que concertar voluntades para presentar un frente común, para hacer valer nuestros intereses, para dar nuestra visión particular de lo que acontece en la esfera internacional.

Si hubiera que señalar, en orden de prioridades, la importancia de la Cumbre de Guadalajara, sin duda, habría que empezar por el mero hecho de que, por primera vez en la historia, los mandatarios de los países iberomareicanos se reunieron formalmente para hablar de asuntos que les interesaran a todos. El segundo aspecto sería la recuperación, o mejor dicho la reinvención del concepto "iberoamericano". A los países de habla hispana y portuguesa del otro lado del Atlántico, nos gustaba que se nos llamara "latinoamericanos"; ahora ya no sólo no nos molesta que se nos llame "iberoamericanos", sino que por el contrario nos complace, por el nuevo contenido del término. España y Portugal, países ibéricos, son, a partir de Guadalajara, también americanos. En tercer lugar, habría que resaltar lo atinado de haber celebrado la primera Reunión al otro lado del Atlántico. Esto, en efecto, diluyó algunos recelos por parte de América Latina de un supuesto y pretendido protagonismo por parte de España y situó a este país como uno más de la comunidad iberoamericana, alejando la imagen del concepto -ahora superado- de la "madre patria", que no beneficia ni a España ni a América Latina en vísperas del siglo XXI.

Pero quedarse en ese nivel conceptual y simbólico, sería insuficiente para los tiempos que corren. Es necesario hacernos más competitivos, en este nuevo contexto internacional y para ello hay que avanzar por el camino de la integración, tanto regional como subregional- manteniendo nuestra soberanía. El proceso no es sencillo, toma su tiempo. Lo primero ha sido concertar las voluntades políticas de nuestros Gobiernos para hacer frente a los retos que se nos presentan. despues, convertir el conjunto de afinidades históricas y culturales -más importantes que las de la Commonwealth o de la francofonía- en un instrumento de unidad y desarrollo. Una unidad que se irá tejiendo a traves del diálogo, la cooperación y la solidaridad, -tal como se señala en la Declaración de Guadalajara. Y, como marco de referencia: el respeto al Derecho Internacional, donde los principios de la democracia y el respeto a los derechos humanos se combinan con los principios de la soberanía y la no intervención.

En el plano operativo, se apoyan y fomentan los procesos de integración tanto regional como subregional. Las reuniones del Grupo de Río, del Grupo de los Tres, no son incompatibles con las de los países centroamericanos, ni con las del Pacto Andino y Mercosur. Los acuerdos bilaterales, como el suscrito entre México y Chile, son también bienvenidos y se consideran como parte de un entramado más amplio que se empieza a urdir.

En el ámbito latinoamericano estos procesos són complejos: las diferencias entre los distintos niveles de desarrollo, en el monto y condiciones de la deuda pública, las disparidades sociales y en el distinto nivel de integración de cada uno de los países con que otros socios, marcan los límites del alcance de esta iniciativa.

Si en el plano latinoamericano la integración es compleja, en el nivel iberoamericano el proceso es aún más complicado. No hay que crear falsas expectativas y hay que caminar despacio, pero firmemente y avanzar en terrenos completos. Somos conscientes de que la pertenencia geográfica, política y económica de España y Portugal a Europa y más concretamente a la Comunidad Europea (CE), marca algunas limitaciones en este proyecto conjunto, 
pero también sabemos que favorece el diálogo interregional entre América Latina y Europa. No se pretende ahora crear una comunidad económica iberoamericana, puesto que la normativa de la CE limita a los países ibéricos. Tampoco pretendemos crear un espacio laboral común, por las restricciones que la CE impone en materia migratoria. Sabemos que el grado de desarrollo económico de España y Portugal, con medianas potencias, no les permite aportar a Latinoamérica grandes ayudas económicas. Sin embargo, estamos seguros de que sí se dán las condiciones para avanzar en ámbito cultural y educativo y de cooperación tecnológica en campos muy concretos, con proyectos bien definidos que se darán a conocer en la Cumbre de Madrid.

En resumen, se trata de trabajar de manera simultanea en la integración intralatinoamericana y en la iberoamericana, procesos que se complementan y apoyan mutuamente. Para América Latina, contar con un mayor grado de integración le resulta conveniente para convertirse en interlocutor válido de la zona, en el contexto de un mundo cada vez más regionalizado. España y la $\mathrm{CE}$ en general han manifestado su interés en contar con una contraparte latinoamericana que sea capaz de representar los intereses de la región de manera global y por ello, apoyan los procesos de integración. La presencia de España y Portugal en el nuevo foro iberoamericano conviene tanto a los países ibéricos como a los latinoamericanos.

Para España y Portugal contar con un grupo de países, como los latinoamericanos, aumenta su peso y margen de negociación tanto en el ámbito comunitario, equiparándolos a Francia u al Reino Unido -con su francofonía y Commonwealth- como en otros foros internacionales que ván desde la Organización de las Naciones Unidas (ONU), hasta el Fondo Monetario Internacional (FMI) (2), por sólo mencionar algunos. No hay que perder de vista que Latinoamérica es, sin duda, la región del mundo con la que Europa tiene mayores afinidades tanto políticas como culturales. Ambas pertenecen a la civilización occidental.

Desde la perspectiva latinoamericana, contar con socios como España y Portugal, miembros de la CE, facilita las relaciones con la Comunidad. Estos países, que si bien son antes que nada europeos, representan los intereses latinoamericanos en Bruselas mejor que cualquiera otro país comunitario.

Con el propósito de no perderse en grandes declaraciones de intención y avanzar en cuestiones concretas, en
Guadalajara se evitó la creación de una gran plataforma que, quizá en unos años, quedaría vacía de contenido, como ha ocurrido en varias ocasiones en los intentos fallidos de integración latinoamericana. Se trataba más bien de construir, sobre cimientos sólidos, un organismo agil, capaz de impulsar y dar seguimiento a lo que en Guadalajara se inció, con proyectos viables y muy concretos de cooperación. En Guadalajara se sentaron las bases de la Conferencia Iberoamericana, una organización que busca evitar el burocratismo, cuya Secretaría Pro témpore es rotativa y la sustenta el país sede de la reunión anual. Así, fue México el primero que la ejerció; ahora le toca a España y próximamente la asumirá Brasil. Siguiendo un poca la mecánica del funcionamiento de la $\mathrm{CE}$, la Coferencia Iberoamericana contó, en un principio, con una "troika" compuesta por México, por ser la sede de la primera Reunión; España por serlo en 1992; y Brasil porque acogerá la tecera Reunión. Ahora se ha ampliado el grupo a cinco miembros donde siguen participando los paises mencionados, más Colombia y Argentina, que serán sede de las IV y $\mathrm{V}$ Reuniones, respectivamente.

El proceso está iniciado y el mecanismo definido y en funcionamiento. Ahora viene la etapa más dificil, la de consolidarse y avanzar, de tal forma que el proyecto beneficie a los países miembros. Es evidente que la unión de voluntades de los Gobiernos de 19 países tiene un peso político muy importante y que el frente que conforman permitirá tener una mayor capacidad de negociación internacional. Es también posible avanzar y profundizar en el diálogo político entre sus integrantes y, al mismo tiempo, promover la cooperación, sobre todo en el terreno cultural, educativo y tecnológico, y fomentar la solidaridad. Existen, sin embargo, riesgos de que el proyecto no prospere. Para evitarlo habrá que hacer un esfuerzo que permita simultaneamente enfrentar los retos nacionales de cada uno de los países que integran esta Conferencia Iberoamericana y mantener el interes y la voluntad política para seguir avanzando en un proyecto que sin duda les reportará grandes beneficios. La conmemoración del V Centenario del Encuentro entre Dos Mundos, entendido más como un proyecto de futuro que en una revisión histórica, representa el marco idóneo para impulsar esta iniciativa. La II Reunión Cumbre a celebrarse en julio próximo en Madrid es una oportunidad invaluable para continuar la construcción de lo que puede llegar a ser una verdadera Comunidad Iberoamericana de Naciones.

(2) Recuerdese que el Ministerio de Economía y Hacienda de España fue propuesto por el Presidente de México y apoyado por los países iberoamericanos en la Cumbre de Guadalajara para ocupar el puesto de Presidente del Comité Interino del FMI. 